\title{
On-Surface Test of the ATLAS Barrel Toroid Coils: Overview
}

A. Dudarev, C. Berriaud, J. J. Rabbers, F. Broggi, S. Junker, R. Pengo, E. Adli, S. Ravat, L. Deront, E. Sbrissa, G. Olesen, M. Arnaud, J.-M. Rey, P. Vedrine, G. Volpini, A. Foussat, P. Benoit, M. Humeau, R. Leboeuf, V. Stepanov, A. Olyunin, I. Shugaev, N. Kopeykin, and H. H. J. ten Kate

\begin{abstract}
The Barrel Toroid (BT) provides the magnetic field for the muon detectors in the ATLAS experiment at CERN. The Toroid is built up from eight superconducting coils. Each coil consists of two $25 \mathrm{~m} \times 5 \mathrm{~m}$ racetrack shape double pancakes impregnated and pre-stressed inside an aluminum coil casing. The 42-tons cold mass is cooled by forced-flow liquid helium circulating in aluminum pipes glued to its surface. The coils are tested on surface prior to their underground installation. The test program has started in September 2004 and finished in June 2005. This paper describes the test set up and various commissioning tests performed at the ATLAS Magnet Test Facility. It includes the aspects of test preparation, vacuum pumping, leak testing, cooling down, powering and warming up. The 8 coils have passed the tests successfully and have been assembled into the Toroid in the ATLAS cavern. The testing completes the production of the so far largest racetrack coils in the world.
\end{abstract}

Index Terms-Detector magnets, superconductors, toroid.

\section{INTRODUCTION}

$\mathbf{T}$ HE Barrel Toroid [1] of the ATLAS magnet system [2] is currently under final stage of installation in the underground area of the ATLAS experiment at CERN. It consists of eight very large racetrack coils (see Fig. 1). The coils were acceptance tested on surface with a magnetic mirror which attracted them with a nominal force of the final toroidal assembly. The main parameters of the coil are given in Table I.

The coils were assembled and tested in the same place and the testing itself is the final step in the production line which have been organized in the West Area of CERN in 1999-2005. Details of the coil assembly are presented in [3]. Being unique and huge in size, the coils could not be easily moved or stored outside the assembly hall so one of the main constraints for the coil test was the limited testing time. Any delay in the test schedule would cause an interruption of assembly works, which were performed by external companies. The test program was shortened to a minimum. In only a few cases some extra to the main program tests were performed to justify main parameters for the coil acceptance.

Manuscript received September 20, 2005.

A. Dudarev, J. J. Rabbers, S. Junker, R. Pengo, E. Adli, S. Ravat, L. Deront, E. Sbrissa, G. Olesen, A. Foussat, P. Benoit, V. Stepanov, A. Olyunin, I. Shugaev, N. Kopeykin, and H. H. J. ten Kate are with CERN, CH-1211 Genève 23, Switzerland (e-mail: Alexey.Dudarev@cern.ch).

C. Berriaud, M. Arnaud, J.-M. Rey, P. Vedrine, M. Humeau, and R. Leboeuf are with CEA-Saclay, 91191, France.

F. Broggi and G. Volpini are with INFN-LASA, Via F.lli Cervi 201, 20090 Segrate, Italy.

Digital Object Identifier 10.1109/TASC.2005.869549

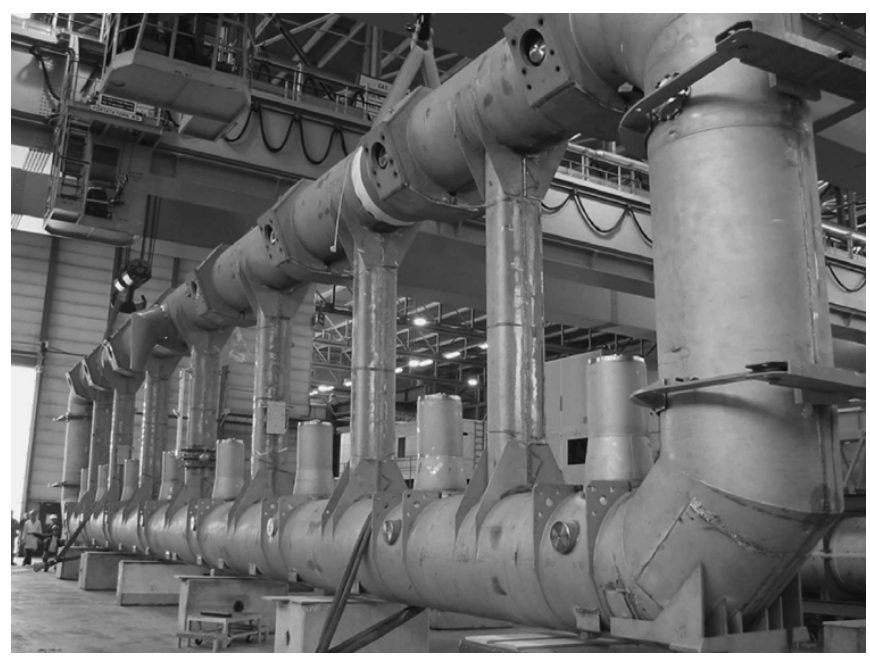

Fig. 1. The individual Barrel Toroid coil has passed the on-surface test in the ATLAS Magnet Test facility and is being prepared for the transport to the underground area of the ATLAS experiment.

TABLE I

MAIN PARAMETERS OF THE BT COILS

\begin{tabular}{ll}
\hline \hline Racetrack dimension & $25 \mathrm{~m} \times 5 \mathrm{~m}$ \\
Weight of the cold mass & $42 \mathrm{ton}$ \\
Operating temperature & $4.6 \mathrm{~K}$ \\
Nominal current & $20.5 \mathrm{kA}$ \\
Self-inductance & $0.56 \mathrm{H}$ \\
Stored energy at $22 \mathrm{kA}$ & $133 \mathrm{MJ}$ \\
\hline \hline
\end{tabular}

In order to save the time for mounting, dismounting and warming up, two testing slots are constructed around the magnetic mirror. In the final toroid the liquid helium flow is supplied from the bottom and there is mirror symmetry between the coils. The two slots were organized correspondingly to accept so called $\mathrm{X}+$ and $\mathrm{X}-$ coils. A swap between them is possible in principle but requires a rather complicated handling and transport operation. Fortunately this option was never used.

The operations needed for the testing and commissioning of each BT coil include the mechanical installation and alignment, mounting of the interfaces to cryogenic, vacuum, electrical and control systems, leak tests and pumping, cooling down and energizing, warming up and disassembly. It is similar to what has to be done for a test of any other superconducting magnet but the exceptional dimensions, time and space constraints have brought some challenges to its realization. The experience of the test campaign of the B0 model coil [4] helped to save time on all operations especially for the testing of the first BT coil [5]. 


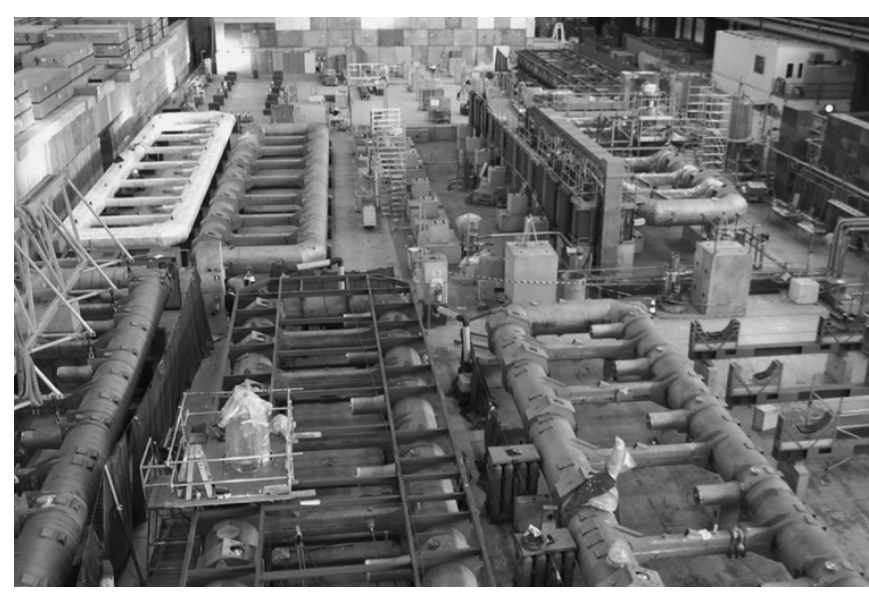

Fig. 2. View on the assembly and test area at a certain moment of assembly in February 2005. A few coils are already installed into the vacuum vessels. One cold mass is prepared for integration. One coil is in the $\mathrm{X}+$ test bench. Being part of the production schedule a delay in the might affect the overall planning.

Particular acceptance criteria are used to characterize the coils during on-surface testing. The detailed analysis of the test results with respect to the acceptance criteria is presented and discussed in [6]. The main steps in the test program includes ramp up to nominal current, test of quench heaters, fast discharge and monitoring of the mechanical and cryogenic behavior. This paper describes the BT coil testing in general with focus on the test set up and various commissioning tests.

\section{GoAls \& CONSTRAints}

Various commercial and technical problems have caused significant delay in the construction of the ATLAS Barrel Toroidal magnet and it started to slow down the construction of the whole ATLAS experiment in the underground cavern. At the early stages of the project the West area of CERN was planed to be used only for the acceptance test of the individual BT coils. Later on it was decided to assemble the coils in this area as well. The area, see Fig. 2, was reorganized to allow to do the assembly works on the cold masses (Integration 1) and with a small shift in time the assembly of the vacuum vessels (Integration 2). In these activities a few companies and institutes were involved under main supervision of the CERN-CEA team. As a result the on-surface test of individual coils was included in the production schedule. The main constraint in this schedule is related to the exceptional dimensions of the constructed objects which can not be easily moved or stored elsewhere. It meant that any delay in the test program would affect the whole production schedule. From the other point of view even the single BT coil is one of the biggest superconducting magnets ever tested in the world and it had to pass the acceptance test to guarantee its reliability for many years of continuous operation in the LHC experiment.

The test station is built only for purpose of testing of the ATLAS coils and the first big object, which is tested there, was the B0 9-meter model coil. The successful test of this prototype has confirmed the design concept of the BT coils and at the same time includes the commissioning of the test facility itself. The major difference between the prototype and the BT coil is their

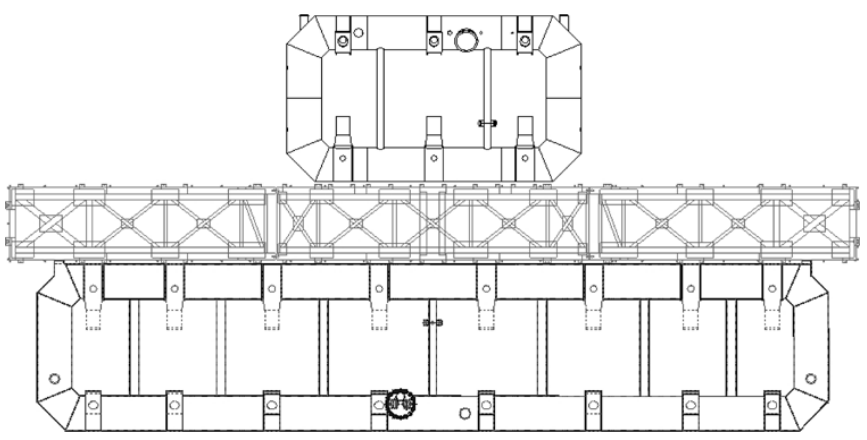

Fig. 3. The difference between B0 and BT coils is mainly in length. Mechanical, power and cryogenic installations are identical for both coils.

length of 9 and $25 \mathrm{~m}$ respectively (Fig. 3) so the test preparation procedures are quite similar for the $\mathrm{BT}$ and the $\mathrm{B} 0$ coils. The $\mathrm{B} 0$ testing also has shown the critical issues in the test set up and has helped to understand the time required for the various test items. The time needed to prepare the B0 for the test was a few months and the test program had taken a few weeks until the maximum current was reached. Such a long time was not acceptable for the coil production. One of the main tasks of the BT coil test team was to minimize drastically the time of the acceptance test but to ensure, at the same time, the highest level of all required controls on these huge superconducting coils.

Specific acceptance criteria have been developed and used to verify the parameters the BT coils during their on-surface testing. The criteria are reflecting the principle parameters required for the safe operation of the ATLAS Toroid during twenty years. They can be presented in a few groups:

Electrical criteria: maximum current up to $22 \mathrm{kA}$ without training steps below $21 \mathrm{kA}$; ground insulation more than $1 \mathrm{M} \Omega$ at $2 \mathrm{kV}$ and $5 \mathrm{~K}$; slow discharge (where $\mathrm{dI} / \mathrm{dt}$ is higher than at ramp up) without quench; fast discharge without damage and a maximum temperature of the quenched double pancake less than $100 \mathrm{~K}$; double pancake resistances below $10^{-8} \Omega$; stability at steady state conditions at $20.5 \mathrm{kA}$ for $10 \mathrm{~h}$;

Vacuum and cryogenic criteria: vacuum is better than $10^{-4}$ mbar under pumping; leak rate of thermal shield and cold mass cooling lines less than $10^{-5} \mathrm{mbar} \times 1 / \mathrm{s}$ at lower temperatures; average cold mass temperature less than $5.2 \mathrm{~K}$; thermal gradients less than $0.5 \mathrm{~K}$; heat load to cold mass less than $150 \mathrm{~W}$; heat load to thermal shield less than $1500 \mathrm{~W}$;

Mechanical criteria: sliding of cold mass on cryostops during thermal cycling; maximum load on single tie-rod less than $225 \mathrm{t}$; flexion of tie-rod with $\varepsilon<300 \mu \mathrm{m} / \mathrm{m}$;

Criteria on internal diagnostic: no failures in sensors for the magnet safety system; not more than one failure per group of sensors for the control system; initiation of normal zone by protection heaters within $10 \mathrm{~s}$ at $5 \mathrm{kA}$ (or $5 \mathrm{~s}$ at $22 \mathrm{kA}$ ).

Based on these criteria a compressed test program was proposed and realized. In only a few cases some additional tests were required to justify the coil performance.

\section{Test Set Up \& MAin Operations}

The test station itself comprises two test slots around the magnetic mirror, a cryogenic plant, a 24-kA power supply, 


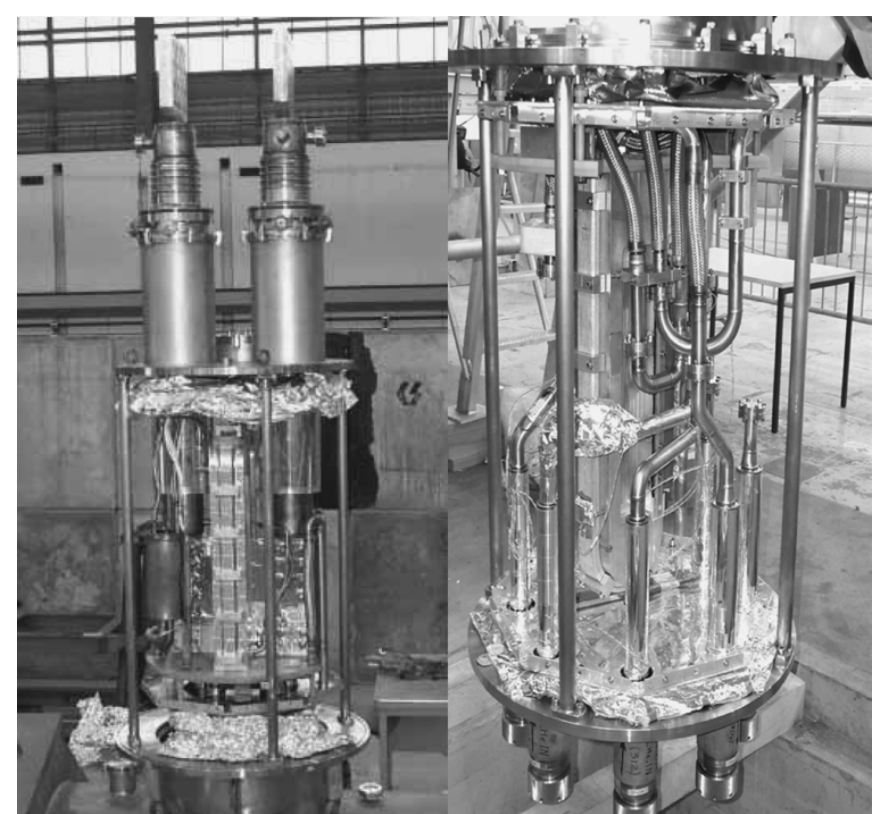

Fig. 4. Interface turrets provide connection to services. Their installation took most of the time prior to start of vacuum pumps. Pressure and leak test were always performed on four independent cooling circuits of each BT coil. The joints were welded in both turrets.

vacuum pumps, Magnet Control (MCS) and Magnet Safety Systems (MSS) [7]. The cryogenic system includes the $1.2 \mathrm{~kW}$ refrigerator cold box, compressors, the pump cryostat containing two immersed centrifugal pumps, distribution valve box, liquid nitrogen pre-cooling unit and two transfer lines feeding the test benches. The power system comprises a $6 \mathrm{~V} / 24 \mathrm{kA}$ switched-mode power converter and a diode/resistor dump unit with an electro-mechanical circuit breaker. MCS provides regulation and monitoring of all the functional parameters of the magnet. It consists of sensors \& actuators, the supervisor system and fast and slow Data Acquisition. For each coil a certain sequence of operations is required to prepare the coil for the acceptance test and to connect it to the external service systems.

\section{A. Installation in Test Bench and Interface Turrets}

The BT coils are assembled in the final toroid at different angles but they were installed and tested horizontally (worst case position) close the magnetic mirror at the test facility. Eight main support units (MSU) link the room temperature heads of the tie-rods to the main frame of the mirror. Each MSU withstands about $25 \mathrm{MN}$ of magnetic force acting between the coil and the mirror. In the overall schedule, movement of the coil to the test slot and its alignment with respect to the magnetic mirror were done in one day and never cause a problem. Mounting of the MSU was also made in the shadow of other activities. Two interface turrets are used for the connections to the external services. The current leads turret (CLT) at the top of the BT test set up contains the electrical and cryogenic connections and joints to the bus bars via current leads. The cryogenic supply turret (CST) at the bottom houses the interconnections of main and redundant cooling circuits to the cryogenic transfer lines and the electrical junction between the two double pancakes

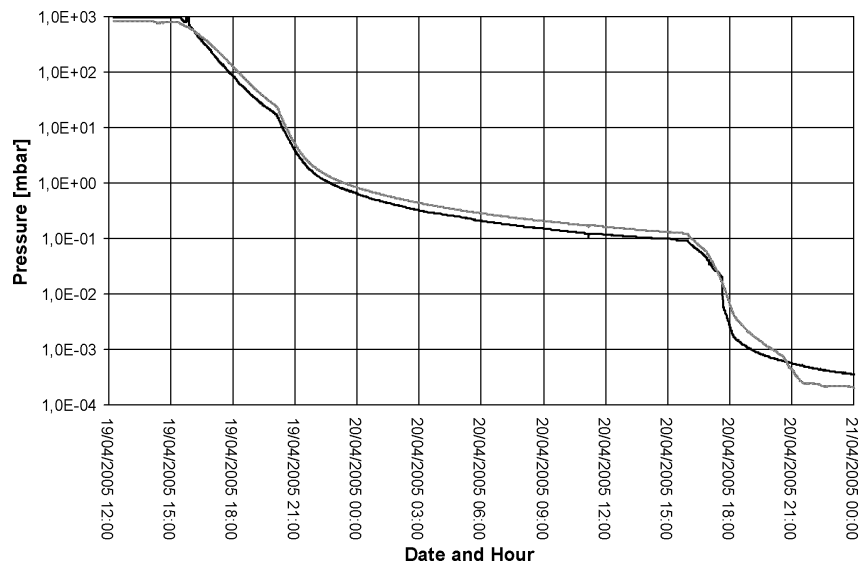

Fig. 5. The typical pump down curve where each change of slope corresponds to a start of one type of pump: at the beginning rotary piston, then roots and diffusion at the end. Cryopumping is not seen here but move the vacuum further down to a level of $10^{-7} \mathrm{mbar}$.

(see Fig. 4). The assembly of these turrets was the most time consuming operation because of many various tests and checks which had to be done before vacuum closing. They include welding of conductors and the connection to the current leads, connections of the cold mass and the thermal shield cooling lines and their leak and pressure testing, installation of diagnostics and vacuum sealing of the turrets. All these steps were well organized and were normally completed within one and a half week. The preparation works were always planned in a way to be finished before weekends to save working time on rough pumping.

\section{B. Vacuum and Leaks}

The vacuum system has two identical branches, one for each test station. Each branch has three pumps, six valves and four pressure gauges. All devices are connected and operated via a remote control system. The pump configuration is designed to cover the necessary range of pressure regimes. The rotary piston pump pumps from atmospheric pressure down to some tens of mbar, when the roots pump is started. The roots pumps bring the pressure to below $10^{-1}$ mbar where the diffusion pump is started. The diffusion pump goes down to about $10^{-4}$ mbar when the cooling down starts. Fig. 5 shows the vessel pressure during the first pumping down of Barrel Toroid coil 7 (it is a typical pumping down curve). The pumping down of the $60 \mathrm{~m}^{3}$ vacuum vessel filled with air at atmospheric pressure to the pressure needed for cool down $\left(10^{-4}\right.$ mbar $)$ took about 30 hours. During cooling down the pressure in the vessels is reduced further by two or three orders of magnitude, reaching an ultimate pressure level about $10^{-6}-10^{-7}$ mbar (values varying from coil to coil). During a fast dump the cold mass temperature rises quickly, and as consequence gas molecules are freed from the surfaces, which causes an increase of the vessel pressure. After a fast dump at high current the vessel pressure was found to increase about two decades during the first hour after a fast dump. With the diffusion pump turned on, the pressure went down again to the ultimate pressure level after two hours. Only one failure happened in the test period: during the rough pumping of the first coil, a part of superinsulation was stuck at the intake 
to the vacuum system. This was due to the fact that the roughing line was evacuated before and a big corner valve that connects the line to the vacuum vessel was opened. The pressure in the line was a few mbar while it was still one atmosphere in the vacuum vessel, a strong air flow was created inside the vessel and it has sucked in the port one blanket of superinsulation. The superinsulation was repaired and the necessary precautions have been taken by installing small bypasses in parallel to big valves.

The leak test of the vacuum vessel started immediately after reaching a reasonable level of the background leak rate. As a rule leak test is performed in two steps. The first step aims to detect big leaks and to fix them quickly in order to start cooling down. The second and more careful search is normally done during cool down when the vacuum is improved by cryopumping. In the case of internal leaks of helium lines the leak tests was done just after the power test when the helium was evacuated from the lines. The leakage rates of each internal line at 20 bars of He pressure is measured at the same time. No significant leaks were found. Details on the leak rates are given in [6].

\section{Cool Down and Warm Up}

Under normal operating conditions the coil is cooled with forced flow liquid helium flowing through pipes attached to the cold mass. The cryogenic system allows the ATLAS coils to be cooled down from ambient temperature to about $80 \mathrm{~K}$, by means of a $10 \mathrm{~kW}$ pre-cooler and capable to maintain a differential temperature of $40-50 \mathrm{~K}$ between the inlet and outlet. The further cooling of the cold mass, from $80 \mathrm{~K}$ to $4.5 \mathrm{~K}$, is achieved using a $1.2 \mathrm{~kW}$ at $4.5 \mathrm{~K}$ refrigerator. The refrigerator cools at the same time the thermal shields of the coil cryostat. After 12 days of cooling the operating temperature is reached. The heat loads of the cold masses at $4.5 \mathrm{~K}$ were obtained by measuring the helium vapor mass flow returning to the refrigerator from the phase separator. The measured load is about or less than $80 \mathrm{~W}$ for all coils and it is almost twice lower than the acceptable value. In details the results of cryogenic tests are presented in [8]. It is important to mention the nonfailure performance of the cryogenic plant during whole test period. The warming up was done by applying some current through the coil and in addition by circulating the He gas through the coil and the heat exchanger of the pre-cooler. The warm up period varies from 5 to 8 days depending on the applied current and the He mass flow.

\section{Powering, Losses and Mechanical Behavior}

The test program with a current took normally one week and it included powering to $5 \mathrm{kA}$ and testing of heaters, ramp up to $16 \mathrm{kA}$ and slow discharge, powering to $22 \mathrm{kA}$ in steps and fast dump, the steady state test at $20.5 \mathrm{kA}$ for $10 \mathrm{~h}$ with ramp up at the end to $22 \mathrm{kA}$ and slow discharge. The nominal current $20.5 \mathrm{kA}$ of the Barrel Toroid was reached without any training in all coils. Only once a training quench was observed in the first double pancake. The mechanical behavior was always monitored and no problems were found. The dynamic losses were measured as well for each coil. The results of power test of the coils are well described in [6], [9] and [10].

\section{CONCLUSION}

The acceptance test of the Barrel Toroid coils was successfully completed in June 2005. Initially being planed to be performed in 15 month the period of the acceptance test was reduced to 12 months including two additional cool down campaigns of the third tested BT coil. Most of the coils have passed the acceptance criteria without any problems. A reduced ground insulation was found in one coil but it could finally be accepted. Only one spontaneous quench has occurred almost at the maximum test current on the first manufactured double pancake. All coils are finally accepted and they are already installed in the underground area of the ATLAS experiment at CERN.

\section{ACKNOWLEDGMENT}

The authors would like to acknowledge all members of the support teams of CERN and CEA-Saclay for their continuous support of all operations during the BT coils testing and commissioning.

\section{REFERENCES}

[1] P. N. Vedrine et al., "Completion of the Manufacturing of the ATLAS Barrel Toroid Magnet at CERN," this conference.

[2] H. H. J. ten Kate, "ATLAS superconducting toroids and solenoid," IEEE Trans. Appl. Supercond., vol. 15, no. 2, pp. 1267-1270, 2005.

[3] J.-M. Rey et al., "Cold Mass Integration of the ATLAS Barrel Toroid Magnets at CERN," this conference.

[4] N. Dolgetta et al., "Review of the ATLAS B0 model coil test program," IEEE Trans. Appl. Supercond., vol. 14, no. 2, pp. 495-504, 2004.

[5] A. Dudarev et al., "First full-size ATLAS barrel toroid coil successfully tested up to $22 \mathrm{kA}$ at 4 T," IEEE Trans. Appl. Supercond., vol. 15, no. 2, pp. 1271-1275, 2005.

[6] C. Berriaud et al., "On-Surface Test of the ATLAS Barrel Toroid Coils: Acceptance Criteria and Results," this conference.

[7] P. Miele et al., "The ATLAS magnet test facility at CERN," IEEE Trans. Appl. Supercond., vol. 11, pp. 1713-1716, 2000.

[8] K. Barth et al., "Results of the cryogenic tests of the superconducting magnets forming the barrel toroid of the ATLAS experiment," presented at the CEC-ICMC, Keystone, Colorado, USA, 2005, 29/8-2/9, unpublished.

[9] C. Mayri et al., "Suspension System of the Barrel Toroid Cold Mass," this conference.

[10] J. J. Rabbers et al., "Theoretical and Experimental Investigation of the Ramp Losses in the Conductor and Coil Casing of the ATLAS Barrel Toroid Coils," this conference. 